\title{
The Functional Organization of Human Extrastriate Cortex: A PET-rCBF Study of Selective Attention to Faces and Locations
}

\author{
James V. Haxby, ${ }^{1}$ Barry Horwitz, ${ }^{2}$ Leslie G. Ungerleider, ${ }^{3}$ Jose Ma. Maisog,, Pietro Pietrini, ${ }^{2}$ and \\ Cheryl L. Grady ${ }^{2}$ \\ 'Section on Functional Brain Imaging, Laboratory of Psychology and Psychopathology, National Institute of Mental Health, \\ 'Laboratory of Neurosciences, National Institute on Aging, and ' ${ }^{2}$ Laboratory of Neuropsychology, National Institute of \\ Mental Health, Bethesda, Maryland 20892
}

The functional dissociation of human extrastriate cortical processing streams for the perception of face identity and location was investigated in healthy men by measuring visual task-related changes in regional cerebral blood flow (rCBF) with positron emission tomography (PET) and $\mathrm{H}_{2}{ }^{15} \mathrm{O}$. Separate scans were obtained while subjects performed face matching, location matching, or sensorimotor control tasks. The matching tasks used identical stimuli for some scans and stimuli of equivalent visual complexity for others. Face matching was associated with selective rCBF increases in the fusiform gyrus in occipital and occipitotemporal cortex bilaterally and in a right prefrontal area in the inferior frontal gyrus. Location matching was associated with selective rCBF increases in dorsal occipital, superior parietal, and intraparietal sulcus cortex bilaterally and in dorsal right premotor cortex. Decreases in rCBF, relative to the sensorimotor control task, were observed for both matching tasks in auditory, auditory association, somatosensory, and midcingulate cortex. These results suggest that, within a sensory modality, selective attention is associated with increased activity in those cortical areas that process the attended information but is not associated with decreased activity in areas that process unattended visual information. Selective attention to one sensory modality, on the other hand, is associated with decreased activity in cortical areas dedicated to processing input from other sensory modalities. Direct comparison of our results with those from other PET-rCBF studies of extrastriate cortex demonstrates agreement in the localization of cortical areas mediating face and location perception and dissociations between these areas and those mediating the perception of color and motion.

[Key words: extrastriate cortex, human, object vision, spatial vision, neuroimaging, cerebral blood flow]

\footnotetext{
Received Dec. 27, 1993; revised Apr. 12, 1994; accepted Apr. 12, 1994.

We thank Drs. Richard Frackowiak and Karl Friston for generously providing the software for Statistical Parametric Mapping. We acknowledge the following people for their contributions: Peter Herscovitch, Richard Carson, and Margaret Daube-Witherspoon for management and care of the NIH PET facility; Jane Gillette, Julie Thompson, Kathryn Giacometti, Kimberly Largay, and Douglas Allen for assistance with task implementation and behavioral testing; Elizabeth Wagner, Judith Salerno, and Arnaldo Gonzalez-Aviles for technical assistance and medical coverage during PET scanning. Finally, we thank Stanley Rapoport, Mark Schapiro, and Mortimer Mishkin for their support and consultation.

Correspondence should be addressed to James V. Haxby, Ph.D., Section on Functional Brain Imaging LPP NIMH, Building 10, Room 4C110, 9000 Rockville Pike, Bethesda, MD 20892.

Copyright (c) 1994 Society for Neuroscience $0270-6474 / 94 / 146336-18 \$ 05.00 / 0$
}

Much of our understanding of primate extrastriate cortex has come from combined anatomical, physiological, and behavioral studies of the monkey brain. The extent of homology between monkey and human extrastriate cortex, however, is still largely undetermined. Studies of monkey visual cortex have shown that there may be over 25 discrete cortical areas, with distinguishable visual field representations, cyto- and myelo-architecture, visual physiology, patterns of connections with other areas, and behavioral effects of lesions (Desimone and Ungerleider, 1989; Felleman and Van Essen, 1991). Visual areas are hierarchically organized, as demonstrated by the patterns of connections between regions (Felleman and Van Essen, 1991). The hierarchy segregates into at least two processing pathways with different visual functions. The most prominent of these are a ventral occipitotemporal pathway for perception of object identity and a dorsal occipitoparietal pathway for the perception of the relative spatial locations of objects, the perception of motion, and the guidance of movements toward objects (Ungerleider and Mishkin, 1982; Desimone and Ungerleider, 1989).

Functional brain imaging studies have confirmed the retinotopic organization of primary visual cortex (Fox et al., 1986, 1987; Schneider et al., 1993) and have identified a small number of foci in extrastriate cortex associated with the perception of color, movement, shape, faces, and spatial locations (Corbetta et al., 1991; Haxby et al., 1991; Zeki et al., 1991; Sergent et al., 1992; Jonides et al., 1993; Watson et al., 1993). The functional dissociation of these foci suggests the existence of separate visual areas. Their locations suggest a hierarchical organization similar to that of the monkey. Color, shape, and face foci have been localized primarily in ventral occipitotemporal cortex, defining at least part of a ventral object vision pathway. The focus for motion perception has been localized to lateral cortex posterior to the ascending limb of the inferior temporal sulcus. Foci for the perception of location have been localized in dorsolateral occipital and superior parietal cortex. These motion and location areas appear to define at least part of a dorsal spatial vision pathway. While it is likely that these general principles of organization are relevant for the study of human visual neuroanatomy, it is unlikely, given the evolutionary distance between humans and monkeys, that a simple one-to-one correspondence between the human and monkey visual areas and interconnections exists.

We have investigated the functional organization of human visual extrastriate cortex by measuring changes in regional cerebral blood flow (rCBF) with PET associated with the pcrception of faces and locations. In this report, we present the results 


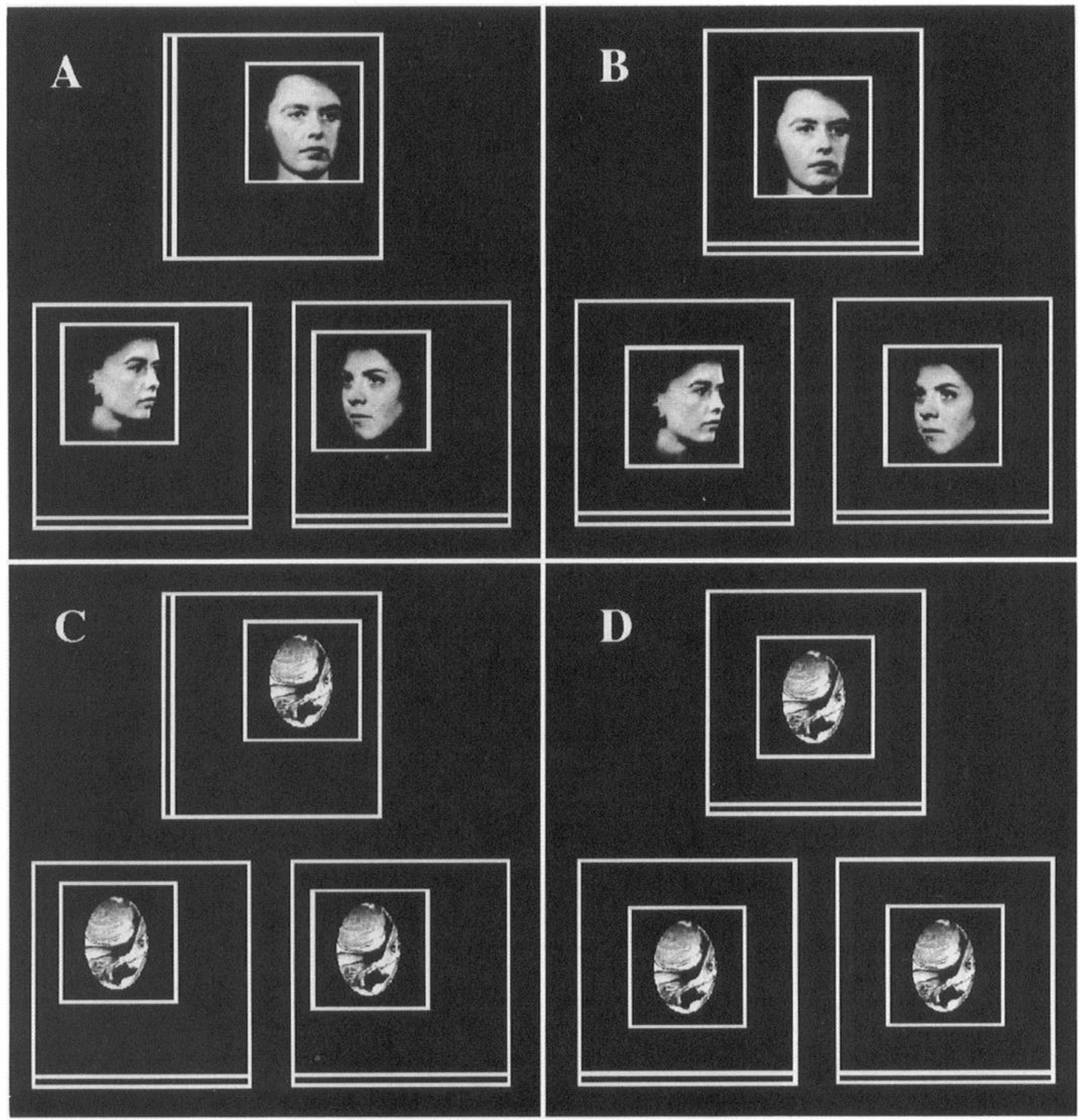

Figure 1. Sample stimuli from the perceptual matching tasks $(A-C)$ and the sensorimotor control task $(D)$. The face matching II and location matching II tasks used identical stimuli $(A)$. For the face matching I task $(B)$, the small square containing the face was always in the center of the larger square and the double line was always on the bottom of each square. For the location matching I $(C)$, the smaller squares contained the same nonsense figure used in the control task stimuli $(D)$.

of an experiment in which the stimuli for face and location perception tasks were matched so that they were either equivalent, in terms of visual complexity, or identical. Thus, the different patterns of $\mathrm{rCBF}$ changes could be assigned unambiguously to differences between face and location perception rather than to stimulus differences. Further, using Talairach and Tour- noux (1988) brain atlas coordinates, we compare our results directly with other PET-rCBF studies of human extrastriate cortex, giving an integrated view of current understanding of the organization of human extrastriate cortex.

Some of these results have appeared in a preliminary report (Haxby et al., 1993). 
Table 1. Mean accuracies and response times for the matching tasks

\begin{tabular}{lll} 
Task & $\begin{array}{l}\text { Accuracy } \\
(\% \text { correct) }\end{array}$ & $\begin{array}{l}\text { Response time } \\
(\mathrm{msec})\end{array}$ \\
\hline $\begin{array}{l}\text { Face matching } \\
\quad \text { Same locations }\end{array}$ & $81 \pm 9$ & $2196 \pm 670$ \\
$\quad \begin{array}{l}\text { Varying locations } \\
\text { Location matching }\end{array}$ & $81 \pm 7$ & $2067 \pm 423$ \\
$\quad$ Nonsense patterns & $92 \pm 6$ & $2372 \pm 531$ \\
Faces & $92 \pm 6$ & $2313 \pm 590$
\end{tabular}

Data are mean \pm SD. Face and location matching accuracies differed significantly $(p<0.01)$. No other differences were significant.

\section{Materials and Methods}

Subjects. Nine healthy, right-handed males participated in this study. Mean age was 29 years $(S D=3)$. All subjects gave written informed consent.

Visual tasks. Six PET scans measuring rCBF were obtained while subjects performed visual matching and control tasks. The stimuli for all tasks used the same basic configuration of three large white squares on a black background, one centered above the other two, which are side by side (Fig. 1). Each large white square had a double line on one side and contained a smaller white square. The smaller squares each contained a complex figure-either a face or a nonsense pattern of equivalent complexity. Faces were taken from the Benton Test of Face Recognition (Benton and Van Allen, 1973). On tasks using the nonsense pattern, the same nonsense pattern was used for all items.

For all visual matching tasks, the subject indicated whether the right or left choice stimulus matched the upper, sample stimulus by pressing a button with his right or left thumb. For the two face matching tasks, the subject indicated which of the choice stimuli contained a picture of the same person shown in the sample stimulus. In one face matching task, face matching $\mathrm{I}$, the smaller squares containing the faces were always centered in the larger squares (Fig. $1 B$ ). In the face matching II task, the position of the smaller squares in the larger squares varied (Fig. 1A). For the two location matching tasks, the subject indicated which of the choice stimuli contained a smaller square in the same location, relative to the double line, as in the sample stimulus. The double line in the sample stimulus was always on either the right side, the left side, or the upper edge of the larger square. The double lines in the choice stimuli were always on the lower edge of the larger squares. In the location matching I task, the smaller squares always contained the nonsense pattern (Fig. $1 C$ ). In the location matching II task, the smaller squares contained pictures of faces (Fig. 1 $A$ ). Thus, the same stimuli were used for the face matching II and location matching II tasks; only the task requirements differed.

In the control task, the double line was always on the lower edge of the larger square, the smaller square was always centered in the larger square, and the smaller square always contained the nonsense pattern (Fig. 1D). On every presentation of the control task stimulus array, the subject pressed a button with either his right or left thumb, in alternating order.

Stimuli were presented as slides projected on a rear projection screen, positioned approximately $55 \mathrm{~cm}$ from the subject's eyes and tilted to be perpendicular to his line of sight. The full stimulus array subtended approximately $17^{\circ}$ of visual angle. Each small square containing a face or nonsense pattern subtended approximately $3^{\circ}$ of visual angle. Each item ended with the subject's response followed by a $1 \mathrm{sec}$ interstimulus interval.

Positron emission tomography. Measurement of rCBF was accomplished with a Scanditronix PC2048-15B tomograph (Milwaukee, WI). This tomograph acquires 15 contiguous, cross-sectional images simul- taneously, each $6.5 \mathrm{~mm}$ thick. Within-plane resolution is $6.5 \mathrm{~mm}$ (full width at half-maximum). Head movement was minimized by using a thermoplastic mask that was molded to each subject's head and attached to the scanner bed.

Each scan was obtained while the subject performed one of the five tasks described above. The first and last scans were obtained during performance of the sensorimotor control task. The second and third scans were obtained during performance of the face matching I and location matching I tasks, with the order counterbalanced across subjects. The third and fourth scans were obtained during performance of the face matching II and location matching II tasks, presented in the same order as the face matching I and location matching I tasks.

Subjects began each task 1 min before the intravenous injection of $40 \mathrm{mCi}$ of $\mathrm{H}_{2}{ }^{15} \mathrm{O}$. Scanning commenced when the brain radioactivity count reached a threshold value and continued for 4 min thereafter. Arterial blood radioactivity was sampled continuously with an automatic blood sampling device from the time of injection to the end of scanning. The visual task was stopped at the end of scanning. A transmission scan was used to correct images for attenuation. rCBF values, in units of $\mathrm{ml} / 100 \mathrm{gm} / \mathrm{min}$, were calculated for each pixel using the sampled arterial blood activity curve and the rapid least squares method (Carson et al., 1987).

Data analysis. The voxel dimensions in the original scans were $2 \times$ $2 \times 6.5 \mathrm{~mm}$. Using linear interpolation, scans were converted to 43 slice images with nearly cubic $2 \times 2 \times 2.17 \mathrm{~mm}$ voxels. Alignment of the first scan in the $y$ (anterior-posterior) and $z$ (superior-inferior) dimensions was rectified using the maximum zero-crossover method described by Minoshima et al. (1992). Scans 2-6 were aligned to the rectified scan 1 using an iterative procedure that tested fit also using the maximum zero-crossover method (Lee et al., 1991) and found the optimum alignment by iterating seven parameters (scale and six movements: roll, pitch, yaw, $\mathrm{x}$-translation, $\mathrm{y}$-translation, $\mathrm{z}$-translation) with the simplex search algorithm (Nelder and Mead, 1965). These procedures corrected all scans for roll, yaw, and between-scan head movements. These programs were implemented on an Intel iPSC 860 parallel supercomputer (Beaverton, OR).

Task-related differences in rCBF were tested using statistical parametric mapping (SPM) (Friston et al., 1989, 1990, 1991a,b). SPM consists of three steps: stereotactic normalization, ANCOVA correction for global flow, and task comparisons. Stereotactic normalization is a fully automated procedure that scales each scan to the dimensions of the Talairach and Tournoux (1988) stereotaxic atlas brain, aligns the scan to the estimated location of the line connecting the anterior and posterior commissures (AC-PC line), and reshapes the scan, using a nonlinear resampling, to the conformation of a template PET scan. Stereotactic normalization resamples each scan into voxels that are $2 \times 2 \times 4 \mathrm{~mm}$ in the $x-, y-$, and $z$-planes, respectively. Scans are then smoothed using a Gaussian filter with a full width at half-maximum of $2 \mathrm{~cm}$ in $\mathrm{x}$ and $\mathrm{y}$, and $1.2 \mathrm{~cm}$ in $\mathrm{z}$. After each individual's scan has been resampled into a standard brain coordinate space, statistics are calculated for each voxel sampled in all subjects. ICBF for each voxel is corrected for variations in global blood flow using ANCOVA. Variance in a voxel is partitioned into variance due to subject, condition, and error. The significance of $\mathrm{rCBF}$ differences between sets of task conditions is tested by calculating $t$ tests using the pooled estimate of error variance. Values of $t$ were converted to standard $Z$ values to provide a measure of statistical significance that is independent of sample size. The criterion for statistical significance was set at $p<0.001$, two-tailed $(\angle=3.38)$.

Comparisons of $\mathrm{rCBF}$ during performance of the two face matching tasks and the two location matching tasks demonstrated that variation of face location during face matching and the presence of faces or nonsense patterns during location matching had no effect. For both comparisons, the number of pixels exceeding any threshold for significance was less than would be expected by chance. Consequently, all analyses treated the two face matching tasks and the two location matching tasks as repeated measures of the same task conditions.

rCBF during performance of face matching was compared both to

\footnotetext{
Figure 2. Areas showing significantly increased rCBF during the perceptual matching tasks as compared to the sensorimotor control task. Coronal sections are adapted from the Talairach and Tournoux stereotaxic atlas. In the coronal sections the right hemisphere is shown on the right and the left hemisphere is on the left. The planc for cach coronal scction is indicated on the lateral views. Tick marks on the frames around cach view on this and all subsequent figures are placed at $1 \mathrm{~cm}$ intervals relative the the location of the anterior commissure.
} 


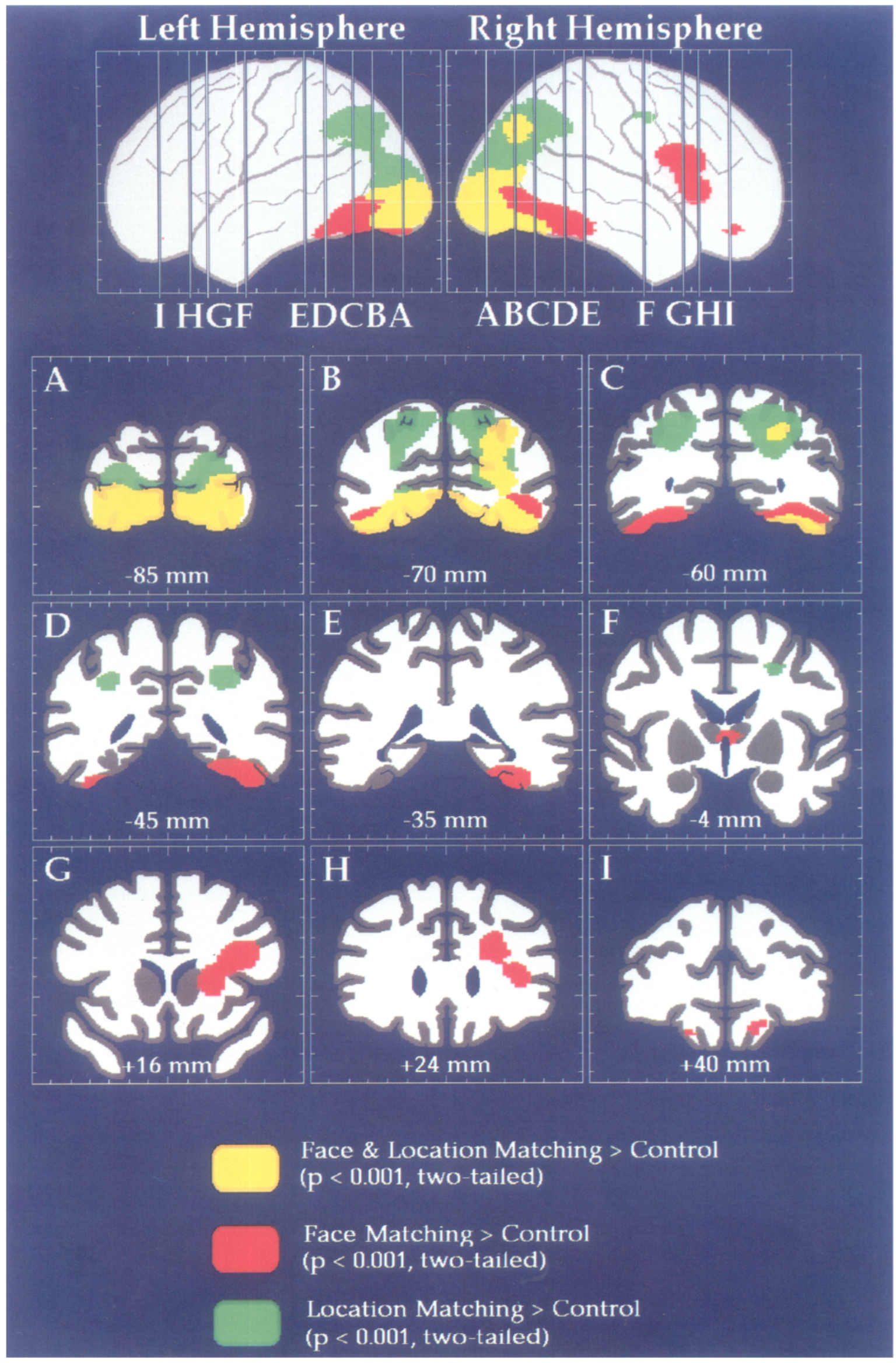


Table 2. Face vision cortical foci

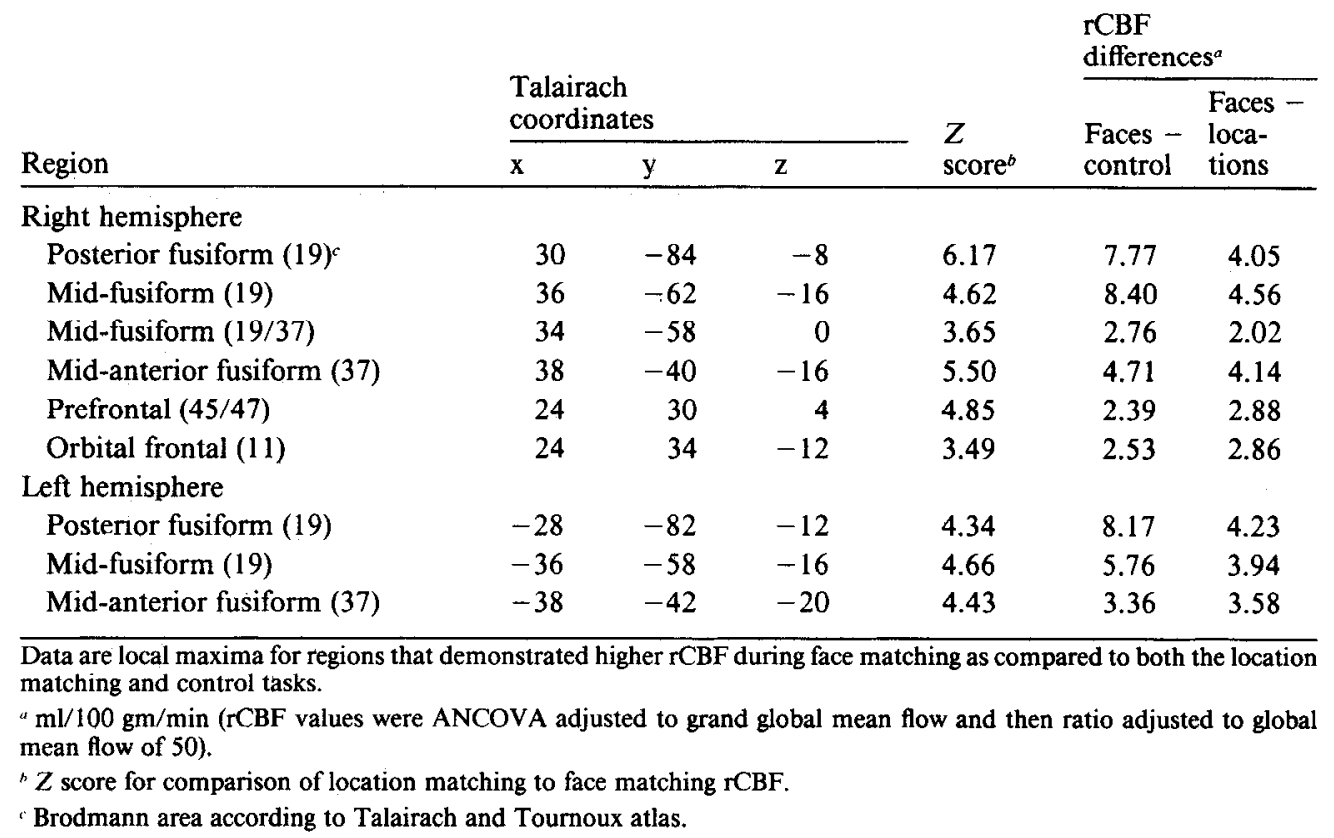

control task rCBF and to location matching rCBF. Similarly, rCBF values during performance of location matching was compared both to control task rCBF and to face matching rCBF. Significant increases as compared to the control task were taken to indicate activation that could be attributable to either general visual processing operations, shared by both tasks. or to visual processing operations specific to object or spatial vision. Significant differences between matching tasks were taken to indicate only areas that performed visual processing operations that were more specific to face or location perception.

Foci for areas demonstrating maximal rCBF differences were identified by finding local maxima, defined as voxels that demonstrated significant $\mathrm{rCBF}$ differences and that had $Z$ values higher than any other voxel in a $2 \mathrm{~cm}$ cube centered on that voxel.

To compare the results of the present study with a previous report (Haxby et al., 1991), the data from that study were reanalyzed using SPM. In the previous report we presented results from a PET-rCBF study of object and spatial vision in which different stimuli were used that were not matched for visual complexity. The earlier study was also conducted on a different set of subjects, using a different tomograph (Scanditronix PC1028-7B, Upsaala, Sweden) with lower axial resolution (seven cross-sectional images, each $11 \mathrm{~mm}$ thick with $3 \mathrm{~mm}$ gaps between slices), and the data were analyzed with a method that did not allow identification of foci with stereotactic brain atlas coordinates.

\section{Results}

Mean response accuracies and latencies are presented in Table 1. Response latencies did not differ for any of the tasks. Accuracy was equivalent for the two forms of face matching and for the two forms of location matching. Accuracy on location matching, however, was significantly better than face matching accuracy $(p<0.01)$.

Areas demonstrating significant increases of rCBF during performance of the face and location matching tasks, relative to control task rCBF ( $p<0.001$, two-tailed), are shown in Figure 2. Both face and location matching tasks activated a large part of the occipital lobe, including calcarine, medial, and lateral areas, shown in yellow in the figure (Fig. $2 A, B$ ). In the right hemisphere the region activated by both tasks also included a region within the posterior occipitoparietal cortex $(B)$. Face but not location matching activated additional areas located in ven- tral occipitotemporal cortex centered on the fusiform gyrus, as shown in red $(C-E)$. Temporal activation associated with face matching did not extend as far rostrally in the left hemisphere as in the right, as shown in the lateral views and in the coronal section from $35 \mathrm{~mm}$ posterior to the anterior commissure $(E)$. The most rostral temporal voxels demonstrating significant increases were $26 \mathrm{~mm}$ posterior to the anterior commissure in the right hemisphere, as compared to $36 \mathrm{~mm}$ in the left hemisphere. Face matching also activated two areas in the right frontal lobea large area in the inferior prefrontal convexity $(G, I I)$ and a smaller area in orbitofrontal cortex $(I)$-and the medial thalamus $(F)$. An even smaller activation in left orbitofrontal cortex was also observed. Location matching, in contrast to face matching, activated additional areas in bilateral dorsolateral occipital cortex $(A, B)$, in bilateral posterior superior parietal cortex extending rostrally to include the intraparietal sulcus $(B-D)$, and in right dorsal premotor cortex $(F)$.

Brain areas demonstrating significant modulation of activity associated with object versus spatial visual processing were identified by direct comparison of rCBF during face and location matching. Areas shown in red in Figure 3 demonstrated significantly greater $\mathrm{rCBF}$ during face matching as compared to both the location matching and the control tasks. Areas shown in green in Figure 3 demonstrated significantly greater rCBF during location matching as compared to both the face matching and the control tasks ( $p<0.001$, two-tailed). The local maxima of these areas, based on differences between face and location matching rCBF, are reported in Tables 2 and 3. Face matching, as compared to the location matching and control tasks, was associated with greater $\mathrm{rCBF}$ in right and left fusiform gyrus (Fig. $3 A-D$ ), in the right inferior frontal gyrus $(F)$, and in right orbitofrontal cortex (not shown in coronal section). Fusiform activation tended to be more extensive in the right as compared to the left hemisphere. Four local maxima were identified in the right fusiform gyrus and three in the left in Brodmann areas 19 and 37, according to Talairach and Tournoux's atlas. Right 


\begin{tabular}{|c|c|c|c|c|c|c|}
\hline \multirow[b]{3}{*}{ Region } & \multirow{2}{*}{\multicolumn{3}{|c|}{$\begin{array}{l}\text { Talairach } \\
\text { coordinates }\end{array}$}} & \multirow[b]{3}{*}{$Z$ score $^{b}$} & \multicolumn{2}{|c|}{$\mathrm{rCBF}$ differences ${ }^{a}$} \\
\hline & & & & & \multirow{2}{*}{$\begin{array}{l}\text { Loca- } \\
\text { tions - } \\
\text { control }\end{array}$} & \multirow{2}{*}{$\begin{array}{l}\text { Loca- } \\
\text { tions - } \\
\text { faces }\end{array}$} \\
\hline & $\mathrm{x}$ & $\mathrm{y}$ & $\mathrm{z}$ & & & \\
\hline \multicolumn{7}{|l|}{ Right hemisphere } \\
\hline Dorsal occipital (19) ${ }^{c}$ & 24 & -76 & 24 & 4.23 & 4.32 & 2.43 \\
\hline Superior parietal (7) & 10 & -58 & 44 & 5.97 & 2.83 & 4.11 \\
\hline Intraparietal sulcus (7) & 32 & -38 & 36 & 4.48 & 2.21 & 3.41 \\
\hline Superior premotor (6) & 24 & -6 & 44 & 4.13 & 3.19 & 3.47 \\
\hline \multicolumn{7}{|l|}{ Left hemisphere } \\
\hline Dorsal occipital (19) & -30 & -80 & 16 & 4.26 & 3.35 & 2.35 \\
\hline Superior parietal (7) & -16 & -64 & 48 & 4.62 & 3.50 & 5.01 \\
\hline Intraparietal sulcus (7) & -36 & -44 & 36 & 4.43 & 3.27 & 3.52 \\
\hline
\end{tabular}

Data are local maxima for regions that demonstrated higher rCBF during location matching as compared to both the face matching and control tasks.

" $\mathrm{ml} / 100 \mathrm{gm} / \mathrm{min}$ (rCBF values were ANCOVA adjusted to grand global mean flow and then ratio adjusted to global mean flow of 50).

${ }^{b} Z$ score for comparison of location matching to face matching rCBF.

c Brodmann area according to Talairach and Tournoux atlas.

inferior frontal activation was maximal in a relatively deep location underlying the inferior frontal gyrus. A small right orbitofrontal focus was in Brodmann area 11. Location matching, as compared to face matching, was associated with greater rCBF bilaterally in dorsal occipital cortex (Brodmann area $19 ; A, B$ ), posterior superior parietal cortex (Brodmann area $7 ; C$ ), and the intraparietal sulcus (Brodmann area $7 ; D$ ), and in superior premotor cortex (Brodmann area $6 ; E$ ) of the right hemisphere.

In addition to areas that demonstrated significant $\mathrm{rCBF}$ increases during the perceptual matching tasks as compared to the control task, areas were found that demonstrated significant rCBF decreases ( $p<0.001$, two-tailed). These areas are shown in Figure 4. Local minima for areas with decreased rCBF are listed in Table 4. Areas with decreased rCBF during face or location matching demonstrated considerable overlap, with local minima in perisylvian, midcingulate, postcentral, and prefrontal areas. The local minima for rCBF decreases associated with face and location matching in these areas were essentially identical, with locations that differed, on average, by only $3 \mathrm{~mm}$ (range, 0-9 $\mathrm{mm}$ ). The areas demonstrating the greatest rCBF decreases for both matching tasks were bilatera! perisylvian cortices with foci (local minima) in the posterior superior temporal gyri (Fig. $4 A, B$ ), insula $(D)$, and primary auditory cortex $(C)$. Midcingulate $(C)$ and small bilateral prefrontal areas $(E, F)$ also demonstrated significant rCBF decreases during both matching tasks. The prefrontal area demonstrating decreased $\mathrm{rCBF}$ in the right hemisphere was more anterior than was the corresponding left hemisphere area. In postcentral sensory cortex, face matching demonstrated more extensive areas of decreased rCBF than did location matching, but local minima for both tasks had identical locations. Face matching, but not location matching, was also associated with rCBF decreases in bilateral medial parietal cortices $(A)$. Location matching was associated, however, with a nearby locus of decreased rCBF in the posterior cingulate cortex $(B)$. A few local minima associated with only one task were found in areas that also showed significant or nearly significant rCBF decreases associated with the other task. These areas were in right midtemporal (location matching), medial superior frontal (location matching), and anterior cingulate (face matching) cortex (not shown in coronal section in the figure).

Generally, these areas demonstrating significant rCBF decreases were in primary and association cortices for unattended sensory modalities, namely, audition and somesthesis. In terms of absolute $\mathrm{rCBF}$, these reductions appeared even larger than the differences in ANCOVA-adjusted rCBF, ranging from 9\% to $17 \%$ reductions during face matching and from $5 \%$ to $10 \%$ reductions during location matching. Because there was a nonsignificant reduction in global flow during the matching tasks as compared to the control task $(1.9 \pm 6.0$ and $0.7 \pm 3.8 \mathrm{ml} /$ $100 \mathrm{gm} / \mathrm{min}$ for face and location matching, respectively), ANCOVA adjustment for global flow tended to diminish the size of these rCBF decreases.

The results of the reanalysis of data from our previous report are presented in Figure 5 and in Tables 5 and 6 . The coronal sections in Figure 5 were taken at the same distance from the anterior commissure as planes A-D in Figure 3 for direct comparison of the two studies. The threshold of significance for displaying pixels demonstrating differences was lowered to $p<$ 0.01 (two-tailed) to facilitate visual comparison, but only maxima exceeding a threshold of $p<0.001$ (two-tailed) are reported in the tables. The size of the areas of significant rCBF differences and the number of local maxima were smaller in the results from the previous study, suggesting that the methods used in the present study were more sensitive, due perhaps to the higher axial resolution of the tomograph and the higher injected dose for each scan. Nonetheless, the location of areas demonstrating significant differences in posterior cortices arc remarkably similar. Occipitotemporal areas demonstrating significantly higher rCBF during face matching as compared to location matching had two local maxima in the fusiform gyrus of each hemisphere, corresponding to the most posterior and anterior fusiform foci in the present study. Displacement of these foci in the two studies ranged from 5 to $15 \mathrm{~mm}$. Foci for areas more activated by location matching than by face matching in the earlier study were found in right dorsal occipital and bilateral posterior superior parietal cortex. These correspond to foci in the present study, with displacements ranging from 2 to $16 \mathrm{~mm}$. A corre- 


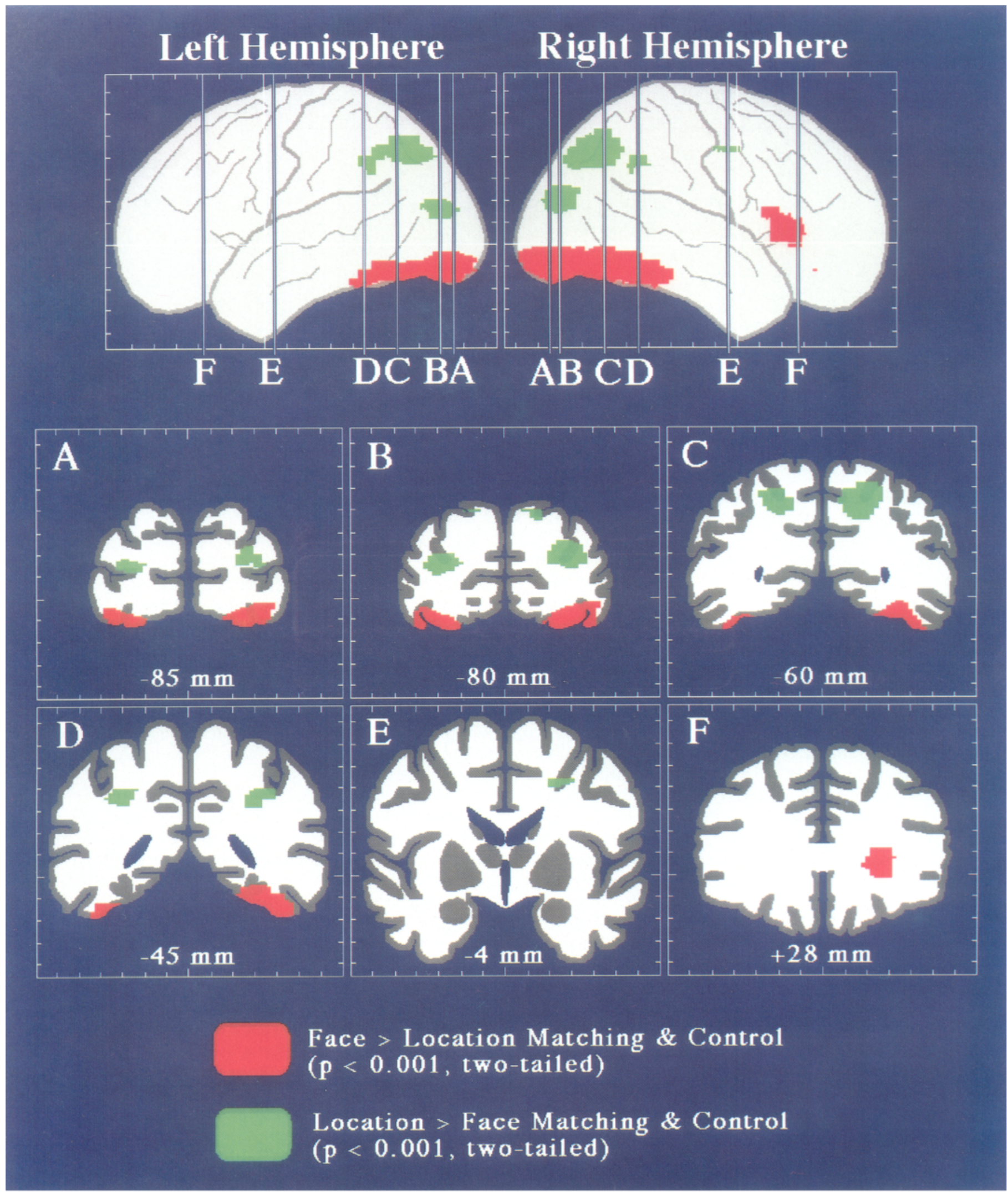

Figure 3. Areas showing significantly higher rCBF during face or location matching as compared to both the other perceptual matching task and the sensorimotor control task. Coronal sections were chosen to correspond to the locations of activation foci (local maxima) listed in Tables 1 and 2 . 


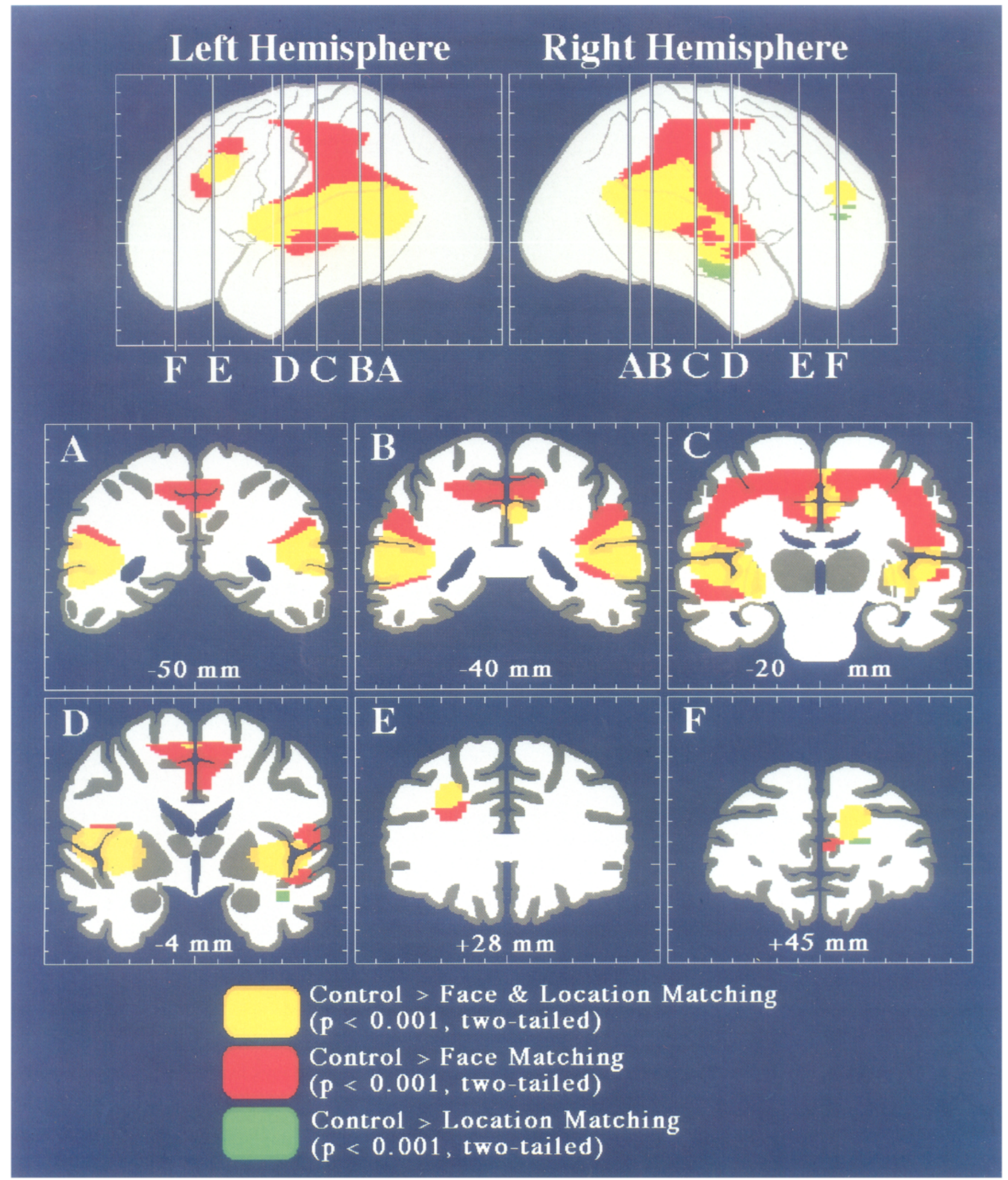

Figure 4. Areas showing significantly decreased rCBF during the perceptual matching tasks as compared to the sensorimotor control task. 
Table 4. Cortical foci (local minima) demonstrating significant rCBF decreases during face or location matching as compared to control task rCBF

\begin{tabular}{|c|c|c|c|c|c|c|c|}
\hline \multirow[b]{3}{*}{ Region } & \multirow[b]{3}{*}{ Task } & \multirow{2}{*}{\multicolumn{3}{|c|}{$\begin{array}{l}\text { Talairach } \\
\text { coordinates }\end{array}$}} & \multirow[b]{3}{*}{$Z$ score $^{b}$} & \multicolumn{2}{|c|}{$\begin{array}{l}\text { rCBF } \\
\text { differences }^{a} \\
\end{array}$} \\
\hline & & & & & & \multirow{2}{*}{$\begin{array}{l}\text { Con- } \\
\text { trol - } \\
\text { faces }\end{array}$} & \multirow{2}{*}{$\begin{array}{l}\text { Con- } \\
\text { trol - } \\
\text { loca- } \\
\text { tions }\end{array}$} \\
\hline & & $\mathbf{x}$ & $\mathrm{y}$ & $\mathbf{z}$ & & & \\
\hline \multicolumn{8}{|l|}{ Right hemisphere } \\
\hline \multirow{2}{*}{$\begin{array}{l}\text { Supcrior temporal } \\
\text { gyrus }(22)^{r}\end{array}$} & Faccs & 48 & -36 & 20 & 7.16 & 6.20 & 4.27 \\
\hline & Locations & 52 & -40 & 20 & 5.74 & 5.26 & 4.31 \\
\hline \multirow[t]{2}{*}{ Insula } & Faces & 38 & -6 & 4 & 5.75 & 4.39 & 4.29 \\
\hline & Locations & 38 & -6 & 4 & 5.75 & 4.39 & 4.29 \\
\hline \multirow[t]{2}{*}{ Postcentral gyrus (1) } & Faces & 52 & -22 & 32 & 6.09 & 3.39 & 2.18 \\
\hline & Locations & 52 & -22 & 32 & 4.52 & 3.39 & 2.18 \\
\hline \multirow{2}{*}{$\begin{array}{c}\text { Superior frontal } \\
\text { gyrus }(9 / 46)\end{array}$} & Faces & 20 & 50 & 24 & 4.50 & 2.18 & 2.06 \\
\hline & Locations & 16 & 46 & 20 & 4.51 & 2.24 & 2.42 \\
\hline Midtemporal (21) & Locations & 48 & -10 & 8 & 4.34 & 2.10 & 1.48 \\
\hline \multicolumn{8}{|l|}{ Precuneus/posterior } \\
\hline cingulate $(7 / 31)$ & Faces & 6 & -50 & 44 & 4.55 & 2.79 & 0.36 \\
\hline \multicolumn{8}{|l|}{ Left hemisphere } \\
\hline \multirow{2}{*}{$\begin{array}{l}\text { Superior temporal } \\
\text { gyrus (22) }\end{array}$} & Faces & -50 & -42 & 20 & $>7.98$ & 5.94 & 4.50 \\
\hline & Locations & -54 & -44 & 20 & 6.33 & 5.30 & 3.99 \\
\hline \multirow[t]{2}{*}{ Primary auditory (41) } & Faces & -46 & -16 & 12 & 6.31 & 5.12 & 3.72 \\
\hline & Locations & -46 & -14 & 12 & 5.20 & 5.05 & 3.73 \\
\hline \multirow[t]{2}{*}{ Insula } & Faces & -36 & -8 & 8 & 6.20 & 4.79 & 3.50 \\
\hline & Locations & -36 & 0 & 12 & 5.38 & 3.89 & 3.22 \\
\hline \multirow[t]{2}{*}{ Postcentral gyrus (1) } & Faces & -46 & -22 & 48 & 4.76 & 2.85 & 1.46 \\
\hline & Locations & -46 & -22 & 48 & 3.59 & 2.85 & 1.46 \\
\hline \multirow[t]{2}{*}{ Midfrontal gyrus $(9 / 46)$} & Faces & -26 & 30 & 28 & 4.95 & 3.20 & 2.23 \\
\hline & Locations & -28 & 26 & 32 & 4.10 & 3.33 & 2.74 \\
\hline \multicolumn{8}{|l|}{ Precuneus/posterior } \\
\hline cingulate $(7 / 31)$ & Faces & -14 & -50 & 48 & 3.83 & 3.44 & 0.41 \\
\hline \multicolumn{8}{|l|}{ Midline } \\
\hline Posterior cingulate ( 31 ) & I ocations & 2 & -44 & 36 & 3.91 & 2.98 & 2.88 \\
\hline \multirow[t]{2}{*}{ Midcingulate (24/31) } & Faces & 0 & -18 & 40 & 6.28 & 5.03 & 3.42 \\
\hline & Locations & 0 & -18 & 40 & 4.89 & 5.03 & 3.42 \\
\hline \multicolumn{8}{|l|}{ Median superior } \\
\hline frontal $(6)$ & Locations & 0 & -10 & 56 & 3.93 & 6.74 & 4.71 \\
\hline Anterior cingulate (32) & Faces & 4 & 40 & 8 & 3.65 & 2.58 & 1.56 \\
\hline
\end{tabular}

${ }^{a} \mathrm{ml} / 100 \mathrm{gm} / \mathrm{min}$ (rCBF values were ANCOVA adjusted to grand global mean flow and then ratio adjusted to global mean flow of 50 ).

" $Z$ score for comparison of control to matching task.

c Brodmann area according to Talairach and Tournoux atlas.

sponding left hemisphere dorsal occipital area can be seen in Figure 5 but failed to achieve statistical significance at $p<0.001$. Local maxima were not found in the intraparietal sulci, but the area demonstrating increased $\mathrm{rCBF}$ during location matching extended into these areas with good spatial agreement with the present study (Figs. 3 and 5, coronal slice C). No right frontal areas demonstrating significant modulation of $\mathrm{rCBF}$ were found that would correspond to the frontal areas found in the present study.

\section{Discussion}

The pattern of $\mathrm{rCBF}$ changes associated with performance of face matching, location matching, and control tasks demonstrates a clear dissociation of visual functions associated with extrastriate visual areas in ventral occipitotemporal and dorsal occipitoparietal cortex. Multiple foci demonstrating maximal rCBF differences were found for each matching task, suggesting that cortical activity evoked by these tasks involved a hierarchy of areas organized as pathways. In addition to bilateral posterior extrastriate areas, right frontal areas selectively activated by these tasks were also found, suggesting the locations of frontal projections zones for human object and spatial visual processing pathways.

Relative to the control task, both visual matching tasks evoked significant rCBF increases in a large part of the occipital lobe, including calcarine, medial, and lateral areas. Because eye movements were not controlled, it cannot be determined whether this activation is due to increased attention to the visual stimuli or to more visual exploration. The areas activated by both tasks 
Table 5. Face vision cortical foci in earlier study (Haxby et al., 1991)

\begin{tabular}{|c|c|c|c|c|c|c|}
\hline \multirow[b]{3}{*}{ Region } & \multirow{2}{*}{\multicolumn{3}{|c|}{$\begin{array}{l}\text { Talairach } \\
\text { coordinates }\end{array}$}} & \multirow[b]{3}{*}{$Z$ score $^{b}$} & \multicolumn{2}{|c|}{$\begin{array}{l}\mathrm{rCBF} \\
\text { differences }\end{array}$} \\
\hline & & & & & \multirow{2}{*}{$\begin{array}{l}\text { Faces - } \\
\text { control }\end{array}$} & \multirow{2}{*}{$\begin{array}{l}\text { Faces - } \\
\text { loca- } \\
\text { tions }\end{array}$} \\
\hline & $\mathrm{x}$ & $\mathrm{y}$ & $\mathbf{z}$ & & & \\
\hline \multicolumn{7}{|l|}{ Right hemisphere } \\
\hline Posterior fusiform (19) ${ }^{c}$ & 34 & -72 & -16 & 4.97 & 7.96 & 4.22 \\
\hline Mid-anterior fusiform (37) & 28 & -40 & -20 & 6.04 & 4.06 & 4.84 \\
\hline \multicolumn{7}{|l|}{ Left hemisphere } \\
\hline Posterior fusiform (19) & -30 & -80 & -8 & 5.52 & 7.41 & 4.27 \\
\hline Mid-anterior fusiform (37) & -38 & 48 & 20 & 4.27 & 2.14 & 3.02 \\
\hline \multicolumn{7}{|c|}{$\begin{array}{l}\text { Data are local maxima for regions that demonstrated higher rCBF during face matching as compared to both the location } \\
\text { matching and control tasks. }\end{array}$} \\
\hline \multicolumn{7}{|c|}{$\begin{array}{l}{ }^{a} \mathrm{ml} / 100 \mathrm{gm} / \mathrm{min} \text { ( } \mathrm{rCBF} \text { values were ANCOVA adjusted to grand global mean flow and then ratio adjusted to global } \\
\text { mean flow of } 50 \text { ). }\end{array}$} \\
\hline
\end{tabular}

may correspond mostly to early visual areas, such as V1, V2, and $V 3$, that precede the major bifurcation of visual pathways into ventral and dorsal processing streams. Our results also suggest, however, that the "object vision" task activatcd some early "spatial vision" extrastriate areas in right occipitoparietal cortex and the "spatial vision" task activated some early "object vision" extrastriate areas in right ventral occipitotemporal cortex (Fig. 2). These activations may reflect inadvertent processing of irrelevant object or spatial information. It is also plausible that face matching necessarily involves some spatial vision operations, such as estimation of the size and relative locations of facial features, and location matching necessarily involves some object vision operations, such as identification of the objects to localize.

Direct comparison of the face and location matching tasks (Fig. 3, Tables 1, 2) identified cortical areas that selectively modulated their activity depending on whether the focus of selective attention was face identity or location. Face matching was associated primarily with selective rCBF increases in a long strip of cortex in the right and left fusiform gyri (Brodmann areas 19 and 37). The fusiform area selectively activated by face matching on the right extended $1 \mathrm{~cm}$ farther forward than did the left fusiform activation. Additional areas of increased rCBF were observed in the right prefrontal (Brodmann areas 45 and 47 ) and orbitofrontal cortex (Brodmann area 11). Based on nonhuman primate anatomy, the prefrontal area may represent the frontal projcction of posterior ventral extrastriate cortex (Chavis and Pandya, 1976). Location matching was associated with increased activity in three bilateral posterior extrastriate foci, lateral occipital cortex (Brodmann area 19), posterior superior parietal cortex (Brodmann area 7 ), and the intraparietal sulcus (Brodmann area 7), and with a small area of increased rCBF in right superior premotor cortex (Brodmann area 6). A smaller rCBF increase in a homologous left premotor area was also observed but was not statistically significant. This area might be the frontal projection of posterior dorsal extrastriate cortex and could be the frontal eye field, an area heavily interconnected with posterior parietal cortex in nonhuman primates (Chavis and Pandya, 1976; Cavada and Goldman-Rakic, 1989a,b). Because eye movements were not controlled in this experiment, the possibility that the rCBF differences between the two matching tasks are due to differences in eye movements cannot be definitively ruled out. A recent PET-rCBF study of voluntary saccades, however, found a network of areas associated with saccades, including the precentral gyrus, supplementary motor area, midcingulate cortex, lenticular nucleus, and thalamus, none

Table 6. Spatial vision cortical foci in earlier study (Haxby et al., 1991)

\begin{tabular}{|c|c|c|c|c|c|c|}
\hline \multirow[b]{3}{*}{ Region } & \multirow{2}{*}{\multicolumn{3}{|c|}{$\begin{array}{l}\text { Talairach } \\
\text { coordinates }\end{array}$}} & \multirow[b]{3}{*}{$Z$ score $^{b}$} & \multicolumn{2}{|c|}{ rCBF differences ${ }^{a}$} \\
\hline & & & & & \multirow{2}{*}{$\begin{array}{l}\text { Loca- } \\
\text { tions - } \\
\text { control }\end{array}$} & \multirow{2}{*}{$\begin{array}{l}\text { Loca- } \\
\text { tions } \\
\text { faces }\end{array}$} \\
\hline & $\mathbf{x}$ & $\mathrm{y}$ & $\mathbf{z}$ & & & \\
\hline \multicolumn{7}{|l|}{ Right hemisphere } \\
\hline Dorsal occipital (19)c & 26 & -76 & 24 & 4.03 & 3.80 & 2.37 \\
\hline Supcrior parictal (7) & 26 & -58 & 44 & 4.39 & 4.96 & 3.03 \\
\hline \multicolumn{7}{|l|}{ Left hemisphere } \\
\hline Superior parietal (7) & -16 & -62 & 44 & 4.86 & 2.74 & 2.96 \\
\hline
\end{tabular}

Data are local maxima for regions that demonstrated higher rCBF during location matching as compared to both the face matching and control tasks.

${ }^{a} \mathrm{ml} / 100 \mathrm{gm} / \mathrm{min}$ (rCBF values were ANCOVA adjusted to grand global mean flow and then ratio adjusted to global mean flow of 50).

${ }^{h} Z$ score for comparison of location matching to face matching rCBF.

" Brodmann area according to Talairach and Tournoux atlas. 


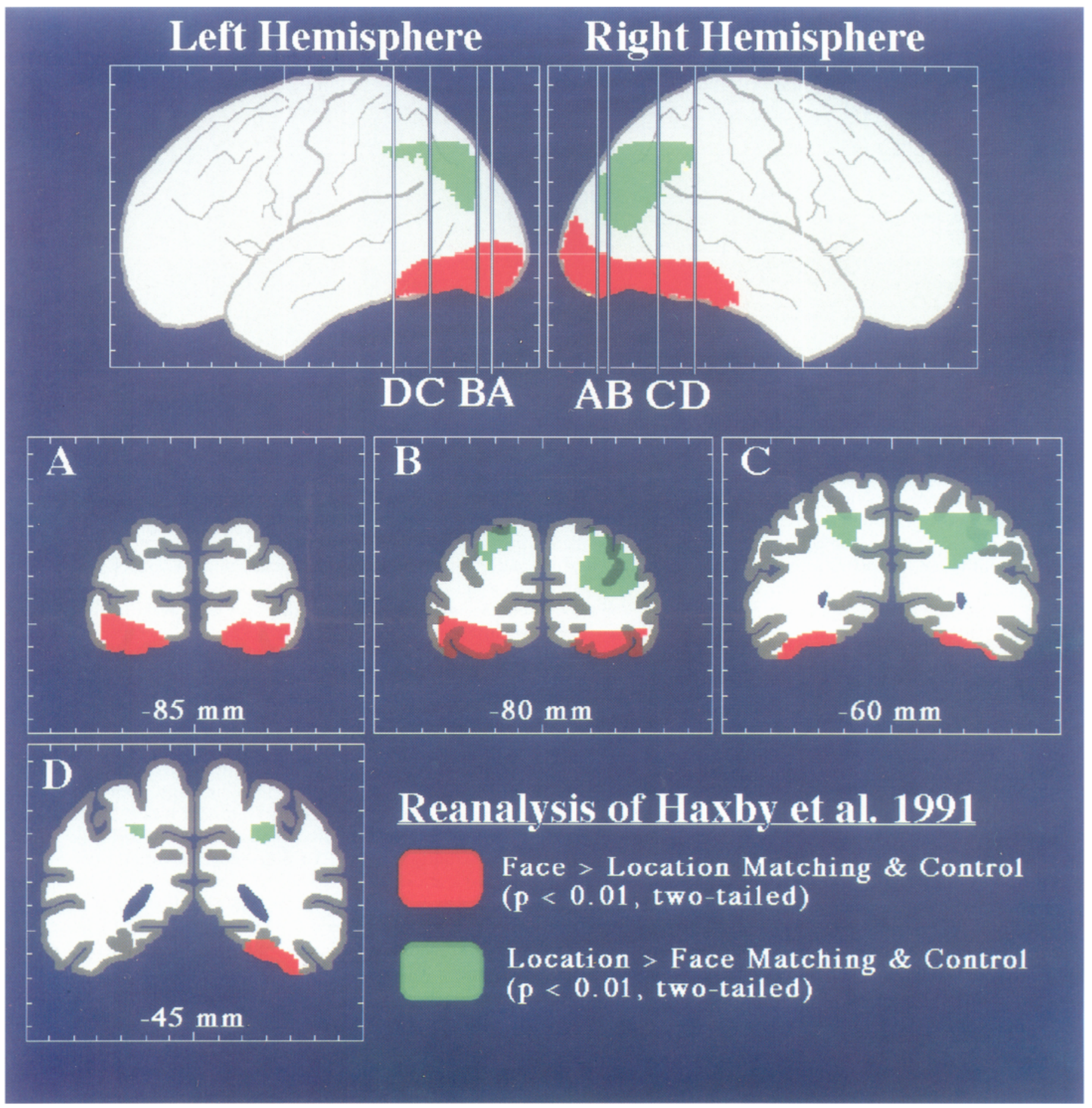

Figure 5. Reanalysis of the data from a previous PET-rCBF study of face and location matching (Haxby et al., 1991). As in Figure 2, the colored areas demonstrated significantly higher $\mathrm{rCBF}$ during face or location matching as compared to both the other perceptual matching task and the sensorimotor control task. The threshold for significance is lower to highlight the similarity between this reanalysis of previous results and the present study. The coronal sections are taken at the same locations as in Figure $2 A-D$ to allow direct comparison.

of which was selectively activated by either the location or face matching tasks (Petit et al., 1993). The locations of the putative frontal eye fields in this recent study and in an earlier PETrCBF study by Fox et al. (1985) were consistently more lateral, in the precentral gyrus, than was the right frontal area selectively activated by location matching, which was located in the su- perior frontal sulcus, suggesting that the premotor area associated with location matching may not be the frontal eye field. Moreover, other PET-rCBF studies of closely related visuospatial functions that did control eye movements also found activation in dorsal prefrontal areas that lie close to the area selectively activated by location matching (see below). 


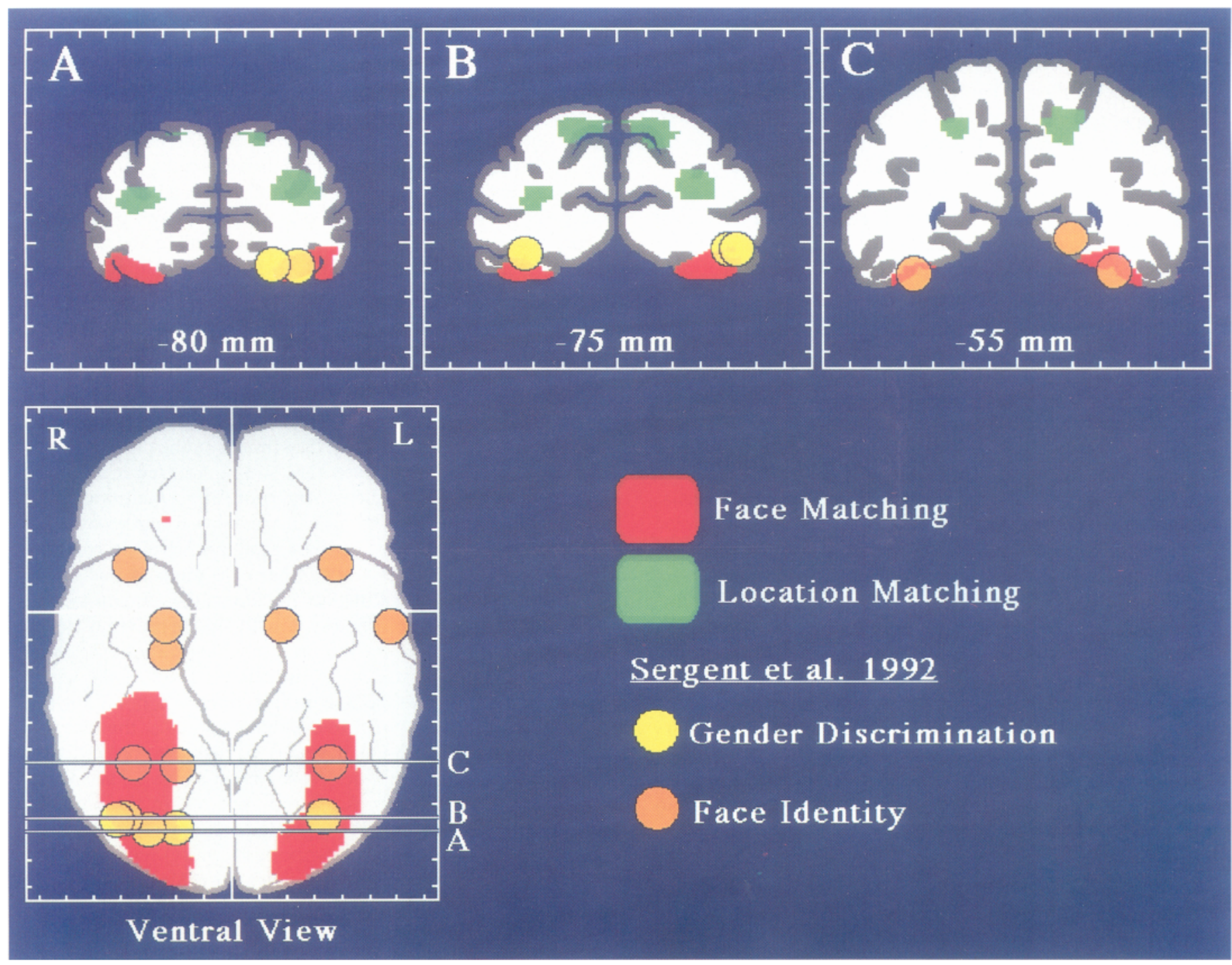

Figure 6. Comparison of areas selectively activated by face matching and a PET-rCBF study of face perception and memory by Sergent et al. (1992). The locations of occipitotemporal foci listed by the Sergent et al. report are shown. Note that in the ventral view the right hemisphere is on the left and the left hemisphere is on the right.

\section{Visual attention and $r C B F$}

Attending selectively to the identity and the locations of faces was associated with the same selective increases in $\mathrm{rCBF}$ whether or not the stimuli contained irrelevant faces or variations in locations. These results suggest that, within a sensory modality, selective attention to one aspect of a stimulus may be mediated, in part, by selective increase in the activity of neural systems that process that type of information. This finding recapitulates that of Corbetta et al. (1991), who found selective activation of cortical areas associated with selective attention to the shape, color, or velocity of a visual stimulus array, and extends that finding to other types of visual information. Neither the Corbetta et al. study nor ours found any evidence for selective reductions of $\mathrm{rCBF}$ in the areas associated with the processing of unattended visual information, suggesting that selective attention within a sensory modality is not associated with suppression of activity of neural systems that process irrelevant information.
Significant rCBF reductions, however, were observed in neocortical areas associated with other sensory modalities. These reductions were observed during performance of both perceptual matching tasks as compared to the sensorimotor control task, although they were more extensive for face matching than for location matching. The regions showing the greatest $\mathrm{rCBF}$ reductions were in primary auditory and auditory association cortex. Somatosensory, midcingulate, and prefrontal regions also showed significant $\mathrm{rCBF}$ reductions. The presence of auditory and somatosensory cortex rCBF reductions suggests that selective attention to visual stimuli may be associated with suppression of neural activity in areas that process input from unattended sensory modalities. The cingulate area showing suppression of activity was in mid- and posterior cingulate, which is believed to perform sensory evaluative functions (Vogt et al., 1993). Corroborating evidence for cross-modal suppression of neural activity can be found in the animal literature (Hernandez-Peon et al., 1956; Hocherman et al., 1976; Oatman, 1976), in studies of evoked potentials in humans (Hackley et 
al., 1990), and in previous human rCBF studies (Mazziotta et al., 1982; Kawashima et al., 1993).

An alternative explanation for the rCBF reductions is hydraulic: increased flow to some areas may decrease the flow to areas that also receive blood from common arteries. The pattern of increases and decreases, however, does not support this explanation. All of the ventral occipital and temporal areas activated by face matching lie within the territory of the posterior cerebral artery (Carpenter and Sutin, 1983). Most of the dorsal areas activated by location matching also lie in the posterior cerebral artery distribution or in the watershed zone between the posterior and middle cerebral arteries. The auditory and somatosensory areas showing decreased flow are all in the middle cerebral artery distribution. A hydraulic explanation of the reduced flow areas, therefore, would have to operate at the circle of Willis, reducing flow to the entire distribution of the middle cerebral artery. The rCBF reductions were much more selective, however, excluding the anterior temporal and frontal parts of the middle cerebral artery distribution.

Together, these results suggest that different neural mechanisms are associated with selective attention within and between sensory modalities. Selective attention to one type of information within a sensory modality appears to be associated with increased activity in areas that process the attended information but not with suppression of activity in areas that process the unattended information. By contrast, selective attention to one sensory modality appears to be associated with suppressed activity in cortical areas that process input from other sensory modalities. This suppression apparently includes the primary projection cortices for the unattended modalities. The site or sites for this suppression of activity, therefore, may be precortical, resulting in decreased input to primary cortices for unattended sensory modalities.

Extensive animal literature on the alteration of sensory neural responses when animals attend to a stimulus in another modality has shown that suppression of input can occur at multiple levels (e.g., Oatman, 1976), although evoked potential studies in humans find consistent cvidencc for cross-modal attention only in potentials of presumed cortical origin (Hackley et al., 1990). A precortical mechanism for gating input could diminish all input from one sensory modality. Selective suppression of information within a sensory modality, on the other hand, could only be achieved after the relevant and irrelevant information have been clearly segregated. Otherwise, a damping of signal could interfere with relevant processing. Adequate segregation of information about different visual features or about visual stimulus identity versus localization requires cortical involvement. Thus, the cortical mechanisms for selective attention that can distinguish between these types of visual information appear to operate by augmenting relevant processing but not by suppressing irrelevant processing.

\section{Reanalysis of results from previous report}

Reanalysis of the data from our previous report (Haxby et al., 1991) allowed direct comparison of the results from these two similar studies. These two studies, performed on different PET scanners with different subjects and different stimuli, are in close agreement on the location of posterior areas selectively activated by the face and location matching tasks. This reanalysis also clarifies some ambiguity about the locations of activated areas in the previous report that resulted from the less precise method of image analysis employed. Compared to the earlier study, the present one found more posterior foci with higher levels of significance in both pathways. This difference probably reflects the greater sensitivity afforded by using a 15-plane tomograph, as opposed to a 7-plane tomograph, with no gaps between slices. The Scanditronix PC1048-7B scanner used for the previous study did not sample data from $3 \mathrm{~mm}$ gaps between slices.

The two studies differ more substantially on the participation of frontal areas in the performance of the matching tasks. Selective $\mathrm{rCBF}$ increases in right prefrontal areas were observed in the present study that were not observed in the previous study. Analyses of interregional correlations in the previous study (Horwitz et al., 1992), however, did demonstrate functional associations involving these prefrontal areas, albeit in the absence of rCBF increases. Although the difference in scanner sensitivity may account for this difference, the change in stimuli is a more likely cause. In the previous study, the stimuli for the two tasks were markedly different, and thus, the nature of the task was readily apparent from the stimuli. In the present study, by contrast, the stimuli were very similar or identical, which may have forced subjects to expend more effort maintaining an internal representation of the task instructions. The present study also used smaller pictures of faces, resulting in lower accuracy and slower response times as compared to the previous study. The frontal activation during face matching, therefore, may also reflect this difference in difficulty. Finally, in the previous study, the location matching task required judgments about the location of a dot. The distances to the nearest sides of the larger square, therefore, were to a common reference point. In the present study, the task required judgments about the location of a small square. Thus, the distances to judge used two different references, namely, two sides of the small square. The frontal activations seen in the present study but not in the previous study, therefore, may reflect several factors, namely, the greater need to maintain an internal (working memory) representation of the task instructions and the increased difficulty as well as complexity of the tasks.

\section{Comparisons with other PET-rCBF studies of human extrastriate cortex}

Face perception. Sergent et al. (1992) have reported another PET-rCBF study of face perception, in which they identified foci activated by two different tasks. A gender discrimination task was used to exemplify an early stage of face perception involving structural processing operations. A face identification task was used to elicit later stages of face perception, involving the perception of unique identity and retrieval of memories associated with the pictured individual. The cortical foci activated by the gender discrimination task, as compared to an orientation discrimination control task, lay in close proximity to the more posterior fusiform foci activated by face matching in the present study (Fig. 6A,B). Differences in locations were $9 \mathrm{~mm}$ on the right (using the mean of Sergent et al.'s four foci), and $13 \mathrm{~mm}$ on the left. The foci activated by Sergent et al.'s face identity task, as compared to the gender discrimination task, included foci that lay near the middle fusiform foci activated by our face matching task $(C)$. Differences in locations were $9 \mathrm{~mm}$ on the right and $5 \mathrm{~mm}$ on the left. Sergent et al.'s face identity task additionally activated more anterior temporal areas in bilateral parahippocampal gyri, in the left middle temporal gyrus, and in the temporal poles.

Comparison of our results with those of Sergent et al. both provides some mutual corroboration and helps to characterize 
the visual functions of the foci of activation. The face matching task we used involved both structural processing and the perception of each face as belonging to a unique individual. Sergent et al.'s results suggest that the more posterior fusiform foci are involved only in the structural processing operations that must precede the perception of unique identity. The face matching task has no memory component-the subject does not associate a name or any other biographical information with any of the faces. Consequently, the more anterior fusiform foci activated by both face matching and face identification are probably associated with the perception of unique identity. The additional anterior temporal foci activated by Sergent et al.'s face identification task, therefore, are more likely associated with the memory functions required to perform the face identity task. Thus, the results of Sergent et al. help to distinguish the functional roles of the foci associated with face matching, and our results help to distinguish the functional roles of the foci associated with Sergent et al.'s face identity task. Furthermore, this comparison suggests that the lack of activation of more anterior temporal cortices associated with face matching does not indicate that the human object vision pathway excludes these arcas.

Spatial vision. Two recent PET-rCBF studies have examined other spatial vision tasks (Corbetta et al., 1993; Jonides et al., 1993). The foci of activation reported in these studies are shown in Figure 7 along with the results from our study.

A report by Corbetta et al. (1993) identified superior parietal and frontal areas associated with shifting the spatial focus of attention. These areas lie in close proximity to thosc arcas activated in the present study by location matching in the intraparietal sulcus (Fig. 7B,C) and, on the right side, in premotor cortex (Fig. $7 D$ ), suggesting that shifting attention to spatial locations may be invoked by enhancement of activity in the extrastriate visual areas associated with the perception of spatial location. Differences in locations for the intraparietal sulcus foci activated by visuospatial attention (using mean location for four foci) and location matching were $9 \mathrm{~mm}$ on the right and $16 \mathrm{~mm}$ on the left. The difference in the locations of the right frontal foci were larger $(19 \mathrm{~mm})$. The possibility that the areas associated with shifting spatial attention are coextensive with those for the perception of location suggests that selective attention for spatial locations is mediated by the same type of mechanism underlying other varieties of visual selective attention, namely, increased activity in the cortical areas that process the attended information.

A PET-rCBF study by Jonides et al. (1993) identified areas associated with working memory for visual spatial location in right dorsolateral occipital, right superior parietal, and right frontal cortex. The right dorsolateral occipital area activated by the Jonides task lies $9 \mathrm{~mm}$ from the dorsolateral occipital area selectively activated by our spatial perception task (Fig. 7A), but appears displaced in the direction of the posterior superior parietal spatial vision area. Their right superior parietal area (Fig. $7 C$ ) lies close to the intraparietal sulcus area identified by our study (location difference $=11 \mathrm{~mm}$ ) and the parietal areas identified in Corbetta et al.'s study of visuospatial attention. Similarly, the location of the right prefrontal area in Jonides et al.'s study (Fig. 7D) is in close agreement with our study of visuospatial perception (location difference $=11 \mathrm{~mm}$ ) and Corbetta et al.'s study of visuospatial attention. The more ventral prefrontal arca is close to the ventral prefrontal area activated by our face matching task.
This comparison of three PET-rCBF studies of visuospatial functions suggests that the areas identified in the study of Jonides et al. are not selectively activated by visuospatial working memory but have more general visuospatial functions including perception and attention with no working memory component. Their finding that these areas had increased rCBF as compared to their location perception control might be due to increased activity related to additional operations related to the shortterm retention of spatial location. A more likely explanation, however, is that their perception control task was not a location perception task but an object perception task. In that task, three dots were presented for a short interval. Then a circle was added to the stimulus display, and the subject had to indicate whether the circle surrounded one of the dots. This task could be seen as an object discrimination task, in which the subject discriminates between an empty circle and a circle containing a dot. The comparison of their working memory task to this object discrimination task, therefore, is quite similar to the comparison in our studies between location matching and face matching tasks, with generally consistent results. Consequently, the rCBF increases in dorsal extrastriate and frontal areas cannot be clearly attributed to working memory, but may be due simply to differences in the nature of perceptual discriminations demanded by their control and activation tasks.

Color and motion perception. Two PET-rCBF studies of color vision have identified an area in the collateral sulcus or lingual gyrus that is associated with both passive viewing of color and with selective attention to color (Corbetta et al., 1991; Zeki et al., 1991). The location of these foci in relation to the areas selectively activated by face matching are shown in Figure 8. These foci lie in close proximity to the most posterior fusiform foci associated with face matching and face gender discrimination. The color foci, however, are consistently medial to the foci selectively activated by face matching, although the separations do not exceed the probable resolving power of PETrCBF methods (see discussion below). The mean differences in locations of face matching and color vision areas were $19 \mathrm{~mm}$ on the right and $12 \mathrm{~mm}$ on the left. The more medial focus associated with color vision was activated in our study during both the face and location matching tasks (compare Figs. $2 B$, 8 ), suggesting that this is an early area in the extrastriate cortical hierarchy that participates in both object and spatial visual processing. Further support for a dissociation between ventral posterior occipitotemporal areas associated with face and color perception comes from recent studies by Allison et al. (1993, 1994), in which evoked potentials to visual stimuli were recorded with electrodes placed on the cortical surface in epilepsy surgery patients. Corbetta et al. (1991) also identified dorsolateral occipital foci associated with selective attention to color. Curiously, these dorsolateral color foci are very close to the foci associated with the location matching task (not shown in Fig. 8), suggesting this area is not as exclusively a spatial vision area as arc the superior parietal and intraparietal sulcus areas.

The studies hy Corbetta et al. (1991) and Zeki et al. (1991) also identified foci near the occipitotemporoparietal junction associated with both the passive perception of movement and selective attention to velocity. A more recent study by Watson et al. (1993) replicated Zeki's study and identified the focus in each of 12 subjects and showed that the location of this functional area, identified on superimposed individual MRI scans, was just posterior to the ascending limb of the inferior temporal sulcus. This motion area was not significantly activated by either 


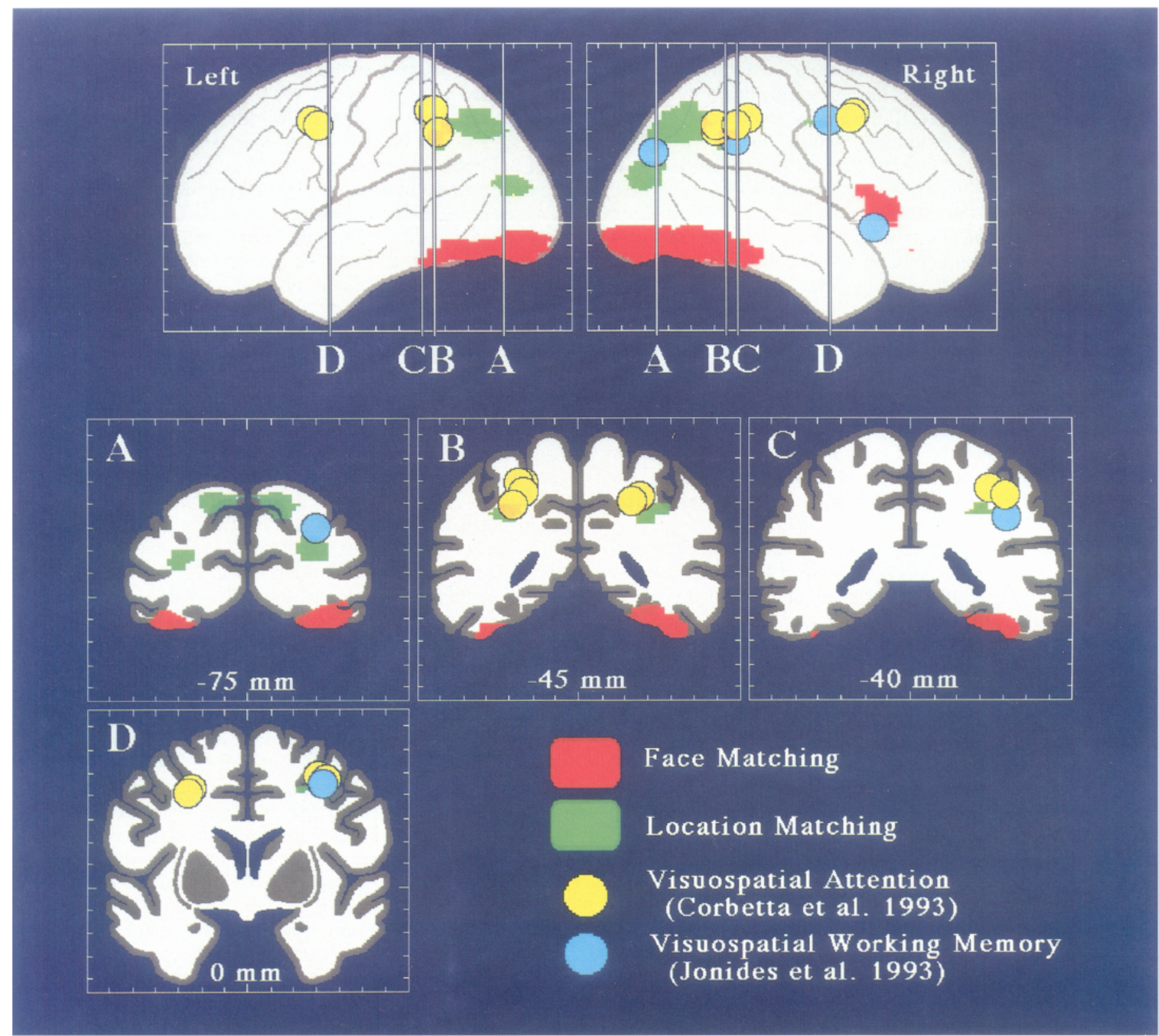

Figure 7. Comparison of areas selectively activated by face and location matching and two other PET-rCBF studies of visuospatial function (Corbetta et al., 1993; Jonides et al., 1993). Foci from the other studies are plotted.

the face matching or the location matching tasks (compare Figs. $2 B, 8)$. Differences in the locations of the motion vision areas identified in Watson et al.'s definitive study and the dorsolateral occipital spatial vision area were $30 \mathrm{~mm}$ on the right and 23 $\mathrm{mm}$ on the left. Converging evidence from these functional brain imaging studies and postmortem anatomical studies (Clarke and Miklossy, 1990) suggests that this motion area is the human homolog for area MT (or MT/MST) in the macaque. Because MT is the major source of projections to parietal extrastriate cortex in the macaque (Felleman and Van Essen, 1991), it is surprising that it was not coactivated with other spatial vision areas during performance of the location matching task. Our PET-rCBF results suggest that a pathway exists in human extrastriate cortex for conveying information about static visual stimuli to parietal cortex for spatial visual processing that circumvents MT.

\section{Spatial precision of $P E T-r C B F$ studies}

The comparisons of the results from the current study with results from our previous study of face and location perception and with results from other PET-rCBF studies of face perception, visuospatial attention and working memory, color perception, and motion perception demonstrates the replicability and precision of PET-rCBF studies of human functional neuroanatomy. Similar studies from the same center but with different tasks, subjects, and tomographs yield agreement on the point locations of functional areas that differ by $2-16 \mathrm{~mm}$ (mean $=$ $7.8 \mathrm{~mm}$ ). Similar studies from different centers with different 


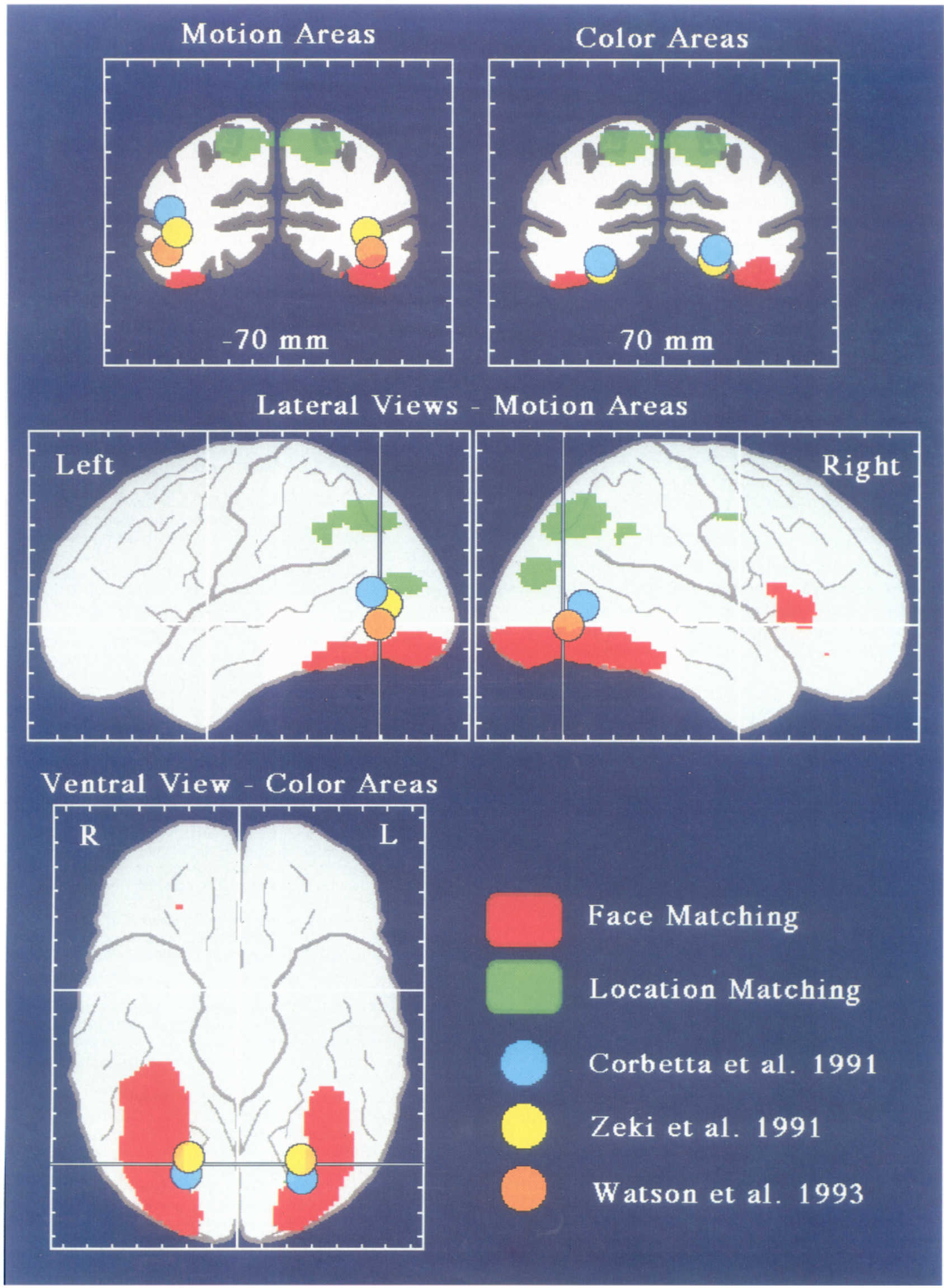

Figure 8. Comparison of areas selectively activated by face and location matching and three PET-rCBF studies of color and motion perception (Corbetta et al., 1991; Zeki et al., 1991; Watson et al., 1993). 
tomographs and different software for image analysis tend to show about the same range of differences. To some extent, these discrepancies are inevitable given the variability in the locations of functional foci across individuals, as exemplified by Watson et al.'s (1993) study of the location of the motion vision area in 12 individual subjects. They found that this focus varied by as much as $27 \mathrm{~mm}$ from one individual to another. With typical sample sizes of 6-10 subjects, therefore, up to $9 \mathrm{~mm}$ differences between group studies would be predicted (maximum difference $/ \sqrt{N}$ ) based on real individual differences. Differences in tomograph, tracer dose, and analysis software could easily account for the additional spatial variation. The real precision of focus identification will vary, of course, with sample size and the size of rCBF changes. These empirical results suggest the limit to spatial resolution for distinguishing functional foci identified by independent PET-rCBF studies, using current methods. Roughly, any difference greater than $2 \mathrm{~cm}$ probably indicates separate foci. Differences smaller than this, on the other hand, cannot be clearly distinguished by a comparison between studies. The power of PET-rCBF studies to distinguish two nearby foci in the same subjects, such as Fox's classic study of retinotopic mapping in human primary visual cortex (Fox et al., 1988), on the other hand, is presumably far greater.

\section{Two visual pathways in human extrastriate cortex}

In the present study, coactivation of multiple areas in extrastriate cortex was observed for both perceptual matching tasks. The locations of these coactivated areas support the hypothesis that cxtrastriate cortex in humans is hierarchically organized with dissociable ventral object vision and dorsal spatial vision systems.

Comparison with other PET-rCBF studies corroborates and elaborates understanding of the organization of these systems. Comparison with Sergent et al. confirms the locations of ventral face perception areas, distinguishes the functional roles of foci within this domain, and suggests the locations of more antcrior temporal areas that may participate in visual memory. Comparisons with other PET-rCBF studies of spatial vision corroborate the locations of dorsal foci in the occipital, parietal, and frontal lobes. Comparisons with studies of color and motion perception suggest the locations of other, relatively early extrastriate visual areas that were not selectively activated by face or location matching. These findings indicate that both the ventral and dorsal visual pathways have multiple routes for input. In the dorsal visual system, the human homolog for MT is not coactivated with areas participating in the perception of the location of static stimuli, suggesting that this area is not the sole or major route for input into this system. In the ventral visual system, early extrastriate areas for color and structural face processing may be functionally dissociable. Both of these areas may be human descendants of area V4 in the macaque. A simple one-to-one mapping of monkey to human visual neuroanatomy is clearly inaccurate. Explication of the locations of human extrastriate visual areas, their patterns of functional connectivity, and the myriad ways they can interact to perform different visual functions is now possible with functional brain imaging, but will require multiple studies using methods that allow direct comparisons of results.

\section{References}

Allison T, Begleiter A, McCarthy G, Roessler E, Nobre AC, Spencer DD (1993) Electrophysiological studies of color processing in hu- man visual cortex. Electroencephalogr Clin Neurophysiol 88:343355.

Allison T, Ginter H, McCarthy G, Nobre AC, Puce A, Luby M, Spencer DD (1994) Face recognition in human extrastriate cortex. J Neurophysiol 71:821-825.

Benton AL, VanAllen MW (1973) Test of facial recognition. Ames, IA: Neurosensory Center, University of Iowa.

Carpenter MB, Sutin J (1983) Human neuroanatomy. Baltimore: Williams and Wilkins.

Carson RE, Berg GW, Finn RD, Patlak CS, Daube-Witherspoon ME, Stein SD, Simpson NR, Green MV, Larson SM (1987) Tomographic measurement of LCBF with high-resolution PET and $\mathrm{H}_{2}{ }^{15} \mathrm{O}$ : comparison of methods. J Ccrcb Blood Flow Metab 7:S578.

Cavada C, Goldman-Rakic PS (1989a) Posterior parietal cortex in rhesus monkey: I. Parcellation of areas based on distinctive limbic and sensory corticocortical connections. J Comp Neurol 287:393421.

Cavada C, Goldman-Rakic PS (1989b) Posterior parietal cortex in rhesus monkey: II. Evidence for segregated corticocortical networks linking sensory and limbic areas with the frontal lobe. J Comp Neurol 287:422-445.

Chavis DA, Pandya DN (1976) Further observation on cortico-frontal connections in the rhesus monkey. Brain Res 117:369-386.

Clarke S, Miklossy J (1990) Occipital cortex in man: organization of callosal connections, related myelo- and cytoarchitecture, and putative boundaries of functional visual areas. J Comp Neurol 298:188214.

Corbetta M, Miezin FM, Dobmeyer S, Shulman GL, Petersen SE (1991) Selective and divided attention during visual discriminations of shape, color, and speed: functional anatomy by positron emission tomography. J Neurosci 11:2383-2402.

Corbetta M, Miezin FM, Shulman GL, Petersen SE (1993) A PET study of visuospatial attention. J Neurosci 13:1202-1226.

Desimone R, Ungerleider LG (1989) Neural mechanisms of visual processing in monkeys. In: Handbook of neuropsychology (Goodglass H, Damasio AR, eds), pp 267-300. Amsterdam: Elsevier.

Felleman DJ, Van Essen DC (1991) Distributed hierarchical processing in the primate cerebral cortex. Cereb Cortex 1:1-47.

Fox PT, Fox JM, Raichle ME, Burde RM (1985) The role of cerebral cortex in the generation of voluntary saccades: a positron emission tomographic study. J Neurophysiol 54:348-369.

Fox PT, Mintun MA, Raichle ME, Miezin FM, Allman JM, Van Essen DC (1986) Mapping human visual cortex with positron emission tomography. Nature 323:806-809.

Fox PT, Miezin FM, Allman JM, Van Essen DC, Raichle ME (1987) Retinotopic organization of human visual cortex mapped with positron-emission tomography. J Neurosci 7:913-922.

Fox PT, Mintun MA, Reiman EM, Raichle ME (1988) Enhanced detection of focal brain responses using intersubject averaging and change-distribution analysis of subtracted PET images. J Cereb Blood Flow Metab 8:642-653.

Friston KJ, Passingham RE, Nutt JG, Heather JD, Sawle GV, Frackowiak RSJ (1989) Localization in PET images: direct fitting of the intercommissural (AC-PC) line. J Cereb Blood Flow Metab 9:690695.

Friston KJ, Frith CD, Liddle PF, Lammertsma AA, Dolan RJ, Frackowiak RSJ (1990) The relationship between local and global changes in PET scans. J Cereb Blood Flow Metab 10:458-466.

Friston KJ, Frith CD, Liddle PF, Frackowiak RSJ (1991a) Comparing functional (PET) images: the assessment of significant change. J Cereb Blood Flow Metab 11:690-699.

Friston KJ, Frith CD, Liddle PF, Frackowiak RSJ (1991b) Plastic transformation of PET images. J Comput Assist Tomogr 15:634-639.

Hackley SA, Woldorff M, Hillyard SA (1990) Cross-modal selective attention effects on retinal, myogenic, brainstem, and cerebral evoked potentials. Psychophysiology 27:195-208.

Haxby JV, Grady CL, Horwitz B, Ungerleider LG, Mishkin M, Carson RE, Herscovitch P, Schapiro MB, Rapoport SI (1991) Dissociation of spatial and object visual processing pathways in human extrastriate cortex. Proc Natl Acad Sci USA 88:1621-1625.

Haxby JV, Grady CL, Horwitz B, Salerno J, Ungerleider LG, Mishkin M, Schapiro MB (1993) Dissociation of object and spatial visual processing pathways in human extrastriate cortex. In: Functional organization of human visual cortex (Gulyas B, Ottoson D, Roland P, eds), pp 329-340. Oxford: Pergamon. 
Hernandez-Peon R, Scherrer H, Jouvet M (1956) Modification of electrical activity in cochlear nucleus during "attention" in unanesthetized cats. Science 123:331-332.

Hocherman S, Benson DA, Goldstein MH, Heffner HE, Hienz RD (1976) Evoked unit activity in auditory cortex of monkeys performing a selective attention task. Brain Res 117:51-68.

Horwitz B, Grady CL, Haxby JV, Ungerleider IG, Schapiro MB, Mishkin M, Rapoport SI (1992) Functional associations among human posterior extrastriate brain regions during object and spatial vision. J Cognit Ncurosci 4:311-322.

Jonides J, Smith EE, Koeppe RA, Awh E, Minoshima S, Mintun MA (1993) Spatial working memory in humans as revealed by PET. Nature 363:623-625.

Kawashima R, O'Sullivan BT, Roland P (1993) A PET study of selective attention in man: cross-modality decreases in activity in somatosensory and visual tasks. J Cereb Blood Flow Metab 13:S502.

Lee KS, Berger KL, Mintun MA (1991) Mathematical registration of PET images enhances detection of neural activation foci by subtraction image analysis. J Cereb Blood Flow Metab 11[Suppl 2]:S557.

Mazziotta JC, Phelps ME, Carson RE, Kuhl DE (1982) Tomographic mapping of human cerebral metabolism: auditory stimulation. Neurology 32:921-937.

Minoshima S, Berger KL, Lee KS, Mintun MA (1992) An automated method for rotational correction and centering of three-dimensional functional brain images. J Nucl Med 33:1579-1585.

Nelder JA, Mead R (1965) A simplex method for function minimization. Comput J 7:308-313.
Oatman LC (1976) Effects of visual attention on the intensity of auditory evoked potentials. Exp Neurol 51:41-53.

Petit L, Orssaud C, Tzourio N, Salamon G, Mazoyer B, Berthoz A (1993) PET study of voluntary saccadic eye movements in humans: basal ganglia-thalamocortical system and cingulate cortex involvement. J Neurophysiol 69:1009-1017.

Schneider W, Noll DC, Cohen JD (1993) Functional topographic mapping of the cortical ribbon in human vision with conventional MRI scanners. Nature 365:150-153.

Sergent J, Ohta S, MacDonald B (1992) Functional neuroanatomy of face and object processing: a positron emission tomography study. Brain 115:15-36.

Talairach J, Tournoux P (1988) Co-planar stereotaxic atlas of the human brain. New York: Thieme.

Ungerleider LG, Mishkin M (1982) Two cortical visual systems. In: Analysis of visual behavior (Ingle DJ, Goodale MA, Mansfield RJW, eds), pp 549-586. Cambridge, MA: MIT Press.

Vogt BA, Finch DM, Olson CM (1993) Functional heterogeneity in cingulate cortex: the anterior executive and posterior evaluative regions. Cereb Cortex 2:435-443.

Watson ID, Myers R, Frackowiak RSJ, Hajnal JV, Woods RP, Mazziotta JC, Shipp S, Zeki S (1993) Area V5 of the human brain: evidence from a combined study using positron emission tomography and magnetic resonance imaging. Cereb Cortex 3:79-94.

Zeki S, Watson JPG, Lueck CJ, Friston K, Kennard C, Frackowiak RSJ (1991) A direct demonstration of functional specialization in human visual cortex. J Neurosci 11:641-649. 